Check for updates

Cite this: RSC Adv., 2020, 10, 33137

Received 25th July 2020

Accepted 28th August 2020

DOI: 10.1039/d0ra06471h

rsc.li/rsc-advances

\section{Ultrafine Pt nanoparticles supported on a dendrimer containing thiol groups: an efficient catalyst for the synthesis of benzimidazoles and benzothiazoles from benzyl alcohol derivatives in water $\dagger$}

\author{
Zahra Zamani Nori, Amir Landarani-Isfahani, (D) Mehrnaz Bahadori, (D) \\ Majid Moghadam, (D) * Valiollah Mirkhani, ${ }^{*}$ Shahram Tangestaninejad (D) \\ and Iraj Mohammadpoor-Baltork (D)
}

\begin{abstract}
A novel and unique platform was prepared based on a dendrimer containing thiol groups supported on nanosilica (nSTDP), and ultrafine platinum nanoparticles were synthesized and immobilized on the thiol decorated branches of nSTPD. The new catalyst, (Pt $t_{n p}$ (anSTDP), was characterized by different techniques such as FE-SEM, TEM, ICP, XPS and DR UV-vis. This heterogeneous catalyst presented an outstanding performance for the synthesis of benzimidazole and benzothiazole derivatives through a reaction between benzyl alcohol derivatives and 2-aminothiophenol or 1,2-phenylenediamine. No requirement for the pre-reduction of catalysts and using water as a green solvent make it an individual catalyst for these reactions. Furthermore, the catalyst can be easily recovered and reused five consecutive times in the production of benzimidazoles and benzothiazoles without significant leaching of $\mathrm{Pt}$ and loss of its activity which illustrated the chemical stability of the catalyst during the reaction.
\end{abstract}

\section{Introduction}

Noble metals have attracted more attention in catalytic systems ${ }^{1}$ and Pt-based catalysts like Pt nanoparticles are one of the most useful and valuable catalysts in chemical reactions. ${ }^{2,3}$ Due to the high cost and scarcity of platinum metal, its immobilizing with preservation of the activity and homogeneous size distribution of nanoparticles is one of the main topics in environmental, economic and safety issues. Different supports such as polymers, ${ }^{4}$ metal-organic frameworks, ${ }^{5}$ metal oxides ${ }^{6}$ and dendrimers ${ }^{7}$ have been used for immobilizing the Pt nanoparticles. But synthesis of structures with a proper surface which minimize the size of particles (less than $5 \mathrm{~nm}$ ) and maximize the efficiency of catalyst by increasing the surface active sites, is still a challenge..$^{8-10}$ Consequently, for the employment of all of the advantages of Pt-nanoparticles, it is important to find a support that can produce very small nanoparticles and prevents their agglomeration. Dendrimer-encapsulated nanoparticles (DES) could be considered as excellent candidates for hosting nanoparticles because of: (a) hyperbranched structure which leads to adsorption of the substrates for performing of reaction

Department of Chemistry, Catalysis Division, University of Isfahan, Isfahan 81746-73441, Iran.E-mail:moghadamm@sci.ui.ac.ir; mirkhani@sci.ui.ac.ir

$\dagger$ Electronic supplementary information (ESI) available. See DOI: $10.1039 / \mathrm{d} 0 \mathrm{ra} 06471 \mathrm{~h}$ efficiently in catalytic systems, (b) control the size of nanoparticles and production of homogeneous nano-metals with narrow size distribution, and (c) tunability of branches for specific interaction with nano-metals and avoiding the agglomeration of them after synthesis. ${ }^{11,12}$

Chandler and co-workers synthesized polyamidoamine (PAMAM) dendrimers for encapsulation of Pt nanoparticles and used it as a precursor for the production of nanoparticle catalysts. ${ }^{13}$ Crooks et. al. have immobilized dendrimer-encapsulated Pt nanoparticles on glassy carbon electrodes and used it for the

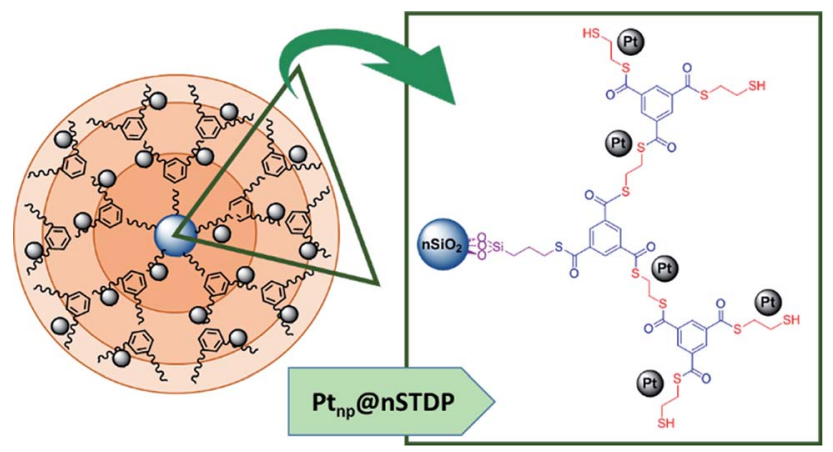

Scheme 1 The structure of immobilized Pt-nano particles on sulfur decorated dendrimer. 


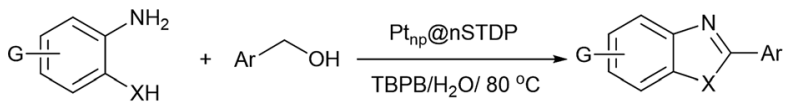

$\mathrm{X}=\mathrm{NH}, \mathrm{S}$

Scheme 2 Synthesis of benzimidazoles and benzothiazoles from alcohols catalyzed by $\mathrm{Pt}_{\mathrm{np}}$ (anSTDP.

$\mathrm{O}_{2}$ reduction reaction (ORR). ${ }^{14}$ Based on the reports on the design of dendrimers with different functional groups such as nitrogen, ${ }^{15}$ oxygen $^{16}$ and sulfur ${ }^{17}$ and the good interaction between platinum and sulfur, ${ }^{18,19}$ the first step of this study is decoration of a dendrimer with sulfur functional group for stabilizing of Pt-nanoparticles. The selection of appropriate central core was the next step in the architecture of the dendrimer structure due to the difficulty of dendrimers separation and the importance of recovery and reusability of DES. ${ }^{20}$ Regarding the ability to be functionalized and benefits of nanosize structures, nano-silica sounds a very intelligently choice for central core of designed dendrimer (Scheme 1).

To confirm the catalytic activity of immobilized Ptnanoparticles on designed dendrimer, the synthesis of benzimidazoles and benzothiazoles was investigated (Scheme 2). Benzimidazoles and benzothiazoles specially 2-substituted ones, are a valuable class of heterocycles that have many applications in biological activities including antitumor, anticancer, and antibacterial, ${ }^{21}$ agricultural chemicals, ${ }^{22}$ and organic functional materials. ${ }^{23}$ Shiraishi and co-workers reported an efficient dehydrogenative coupling reaction for the synthesis of benzimidazole compounds from primary alcohols. ${ }^{24}$ Shimizu et al. reported a new Pt based catalyst for synthesis of 2-substituted benzothiazoles and benzimidazoles from 2-aminothiophenol and 1,2-phenylenediamine with alcohols or aldehydes under acceptor- and additive-free conditions. ${ }^{25}$ But some problems such as pre-reduction of catalyst, using an organic solvent or low yield of the product after recovery of catalyst should be considered.

On the other hands, utilizing water as a green solvent is the most substantial issue in these reactions.

In this project, a sulfur decorated dendrimer based on nano silica was designed, synthesized and applied as a convenient support for the immobilization of Pt-nanoparticles. The activity of the obtained catalyst ( $\left.\mathrm{Pt}_{\mathrm{np}} @ \mathrm{nSTDP}\right)$ was checked for the synthesis of benzimidazoles or benzothiazoles with benzyl alcohol derivatives in water under mild conditions.

\section{Results and discussion}

\section{Characterization}

As illustrated in Scheme 3, the synthesis of $\mathrm{Pt}_{\mathrm{np}} @ \mathrm{nSTDP}$ is started with functionalization of nano-silica and continued by

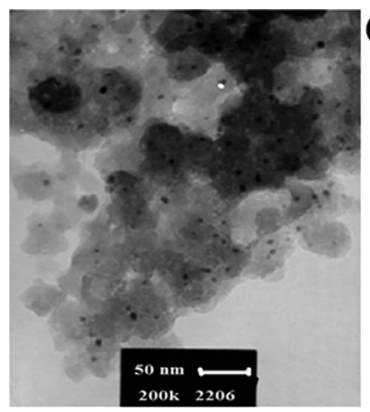

(a)

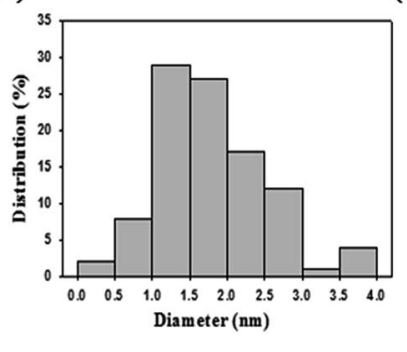

(b)

Fig. 1 (a) TEM image of $\mathrm{Pt}_{n p}$ (anSTDP and (b) particle size distribution histogram of $\mathrm{Pt}_{\mathrm{np}}$ @nSTDP.

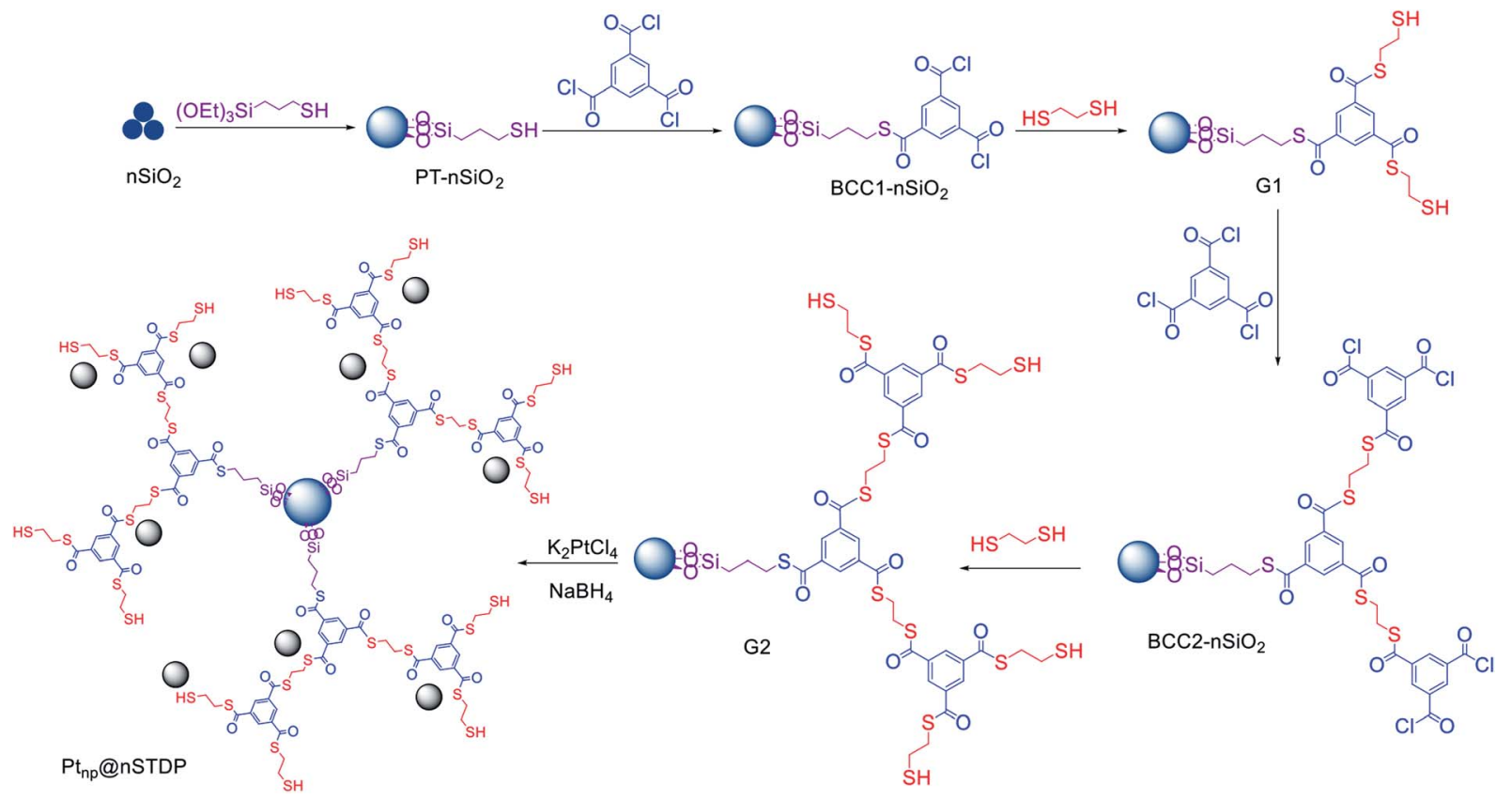

Scheme 3 Synthesis route of $\mathrm{Pt}_{\mathrm{np}}$ anSTPD. 


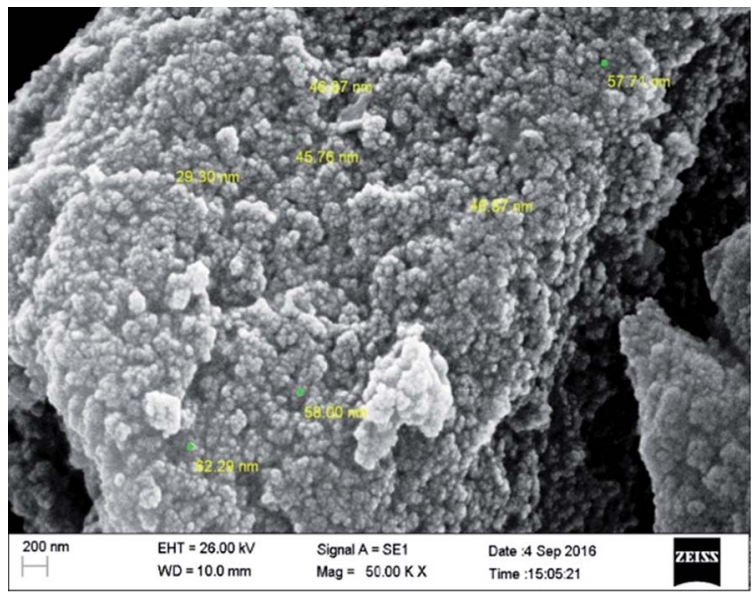

Fig. 2 FE-SEM images of $\mathrm{Pt}_{\mathrm{np}}$ @nSTDP.

growing the thiol dendrimer (divergent growth strategy). Then, the Pt nanoparticles were trapped by the thiol groups of dendrimer via reduction of $\mathrm{K}_{2} \mathrm{PtCl}_{4}$ with $\mathrm{NaBH}_{4}$ to obtain the $\mathrm{Pt}_{\mathrm{np}} @ \mathrm{nSTDP}$.

The step by step synthesis of the $\mathrm{Pt}_{\mathrm{np}} @ \mathrm{nSTDP}$ was monitored by FT-IR spectroscopy. The FTIR spectra for PT-nSiO BCC1-nSiO ${ }_{2}, \mathrm{G} 1, \mathrm{BCC}_{2}-\mathrm{nSiO}_{2}$, and G2 are illustrated in Fig. S1. $\dagger$ The bands at 500, 850, 1150 and $3000-3700 \mathrm{~cm}^{-1}$ are attributed to $\mathrm{Si}-\mathrm{O}$ asymmetric bending, $\mathrm{Si}-\mathrm{O}$ symmetric stretching, $\mathrm{Si}-\mathrm{O}-$ $\mathrm{Si}$ asymmetric stretching and $\mathrm{O}-\mathrm{H}$ stretching in nano-silica or adsorbed water, respectively, which confirmed the presence of nano-silica in all structures. The $\mathrm{C}-\mathrm{H}$ bending band at 1400 and $\mathrm{C}-\mathrm{H}$ stretching bands at $2800-3000 \mathrm{~cm}^{-1}$ display the growth of dendrimer branches in the structures. The characteristic bands at 1700 and $1750 \mathrm{~cm}^{-1}$ correspond to carbonyl groups.

The amount of platinum nanoparticles supported on the dendritic polymer was measured by ICP which showed a value of about $0.06 \mathrm{mmol}$ per gram of the heterogeneous catalyst. One of the main targets of this research is achieving of Pt nanoparticle with size less than $5 \mathrm{~nm}$. Based on TEM images (Fig. 1), we successfully synthesized very small Pt nanoparticle with an excellent size distribution around 1-2 $\mathrm{nm}$.

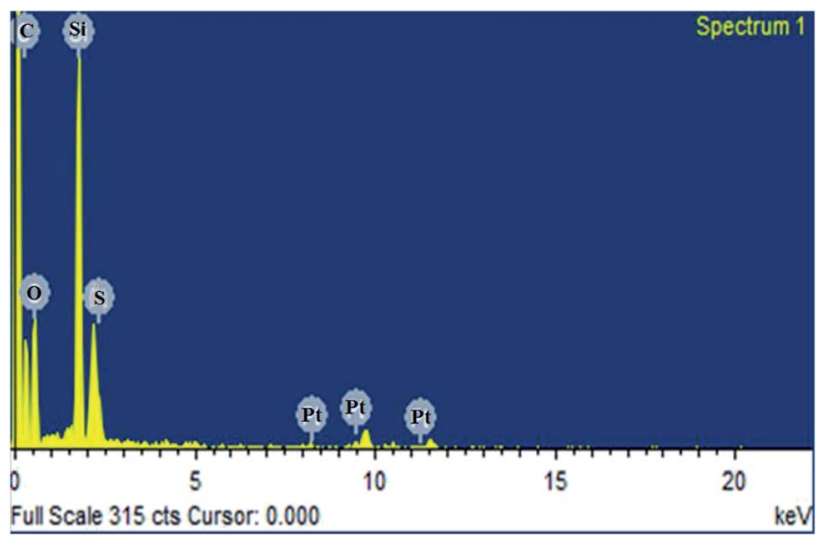

Fig. 3 SEM-EDX spectrum of $\mathrm{Pt}_{\mathrm{np}}$ anSTDP.
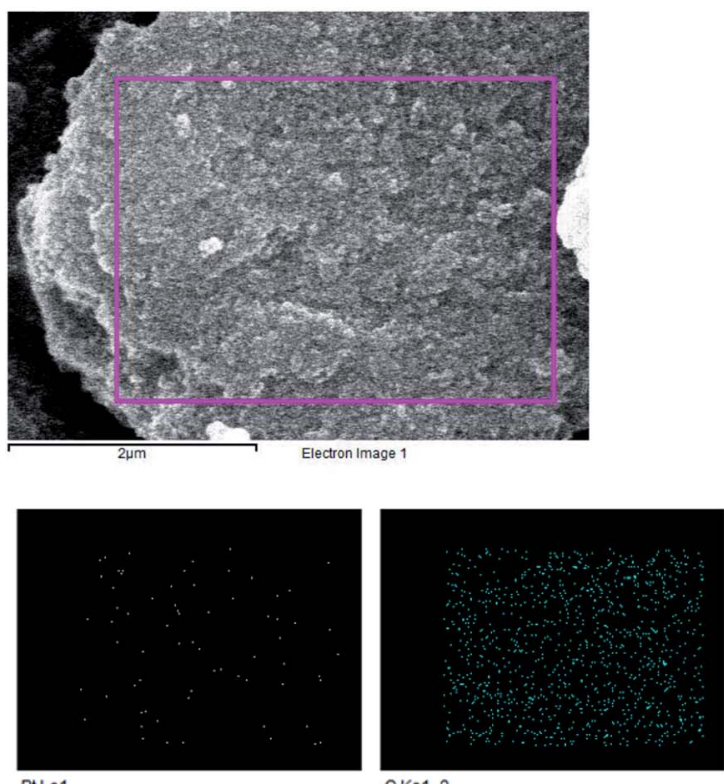

PtLa1 CKa1_2
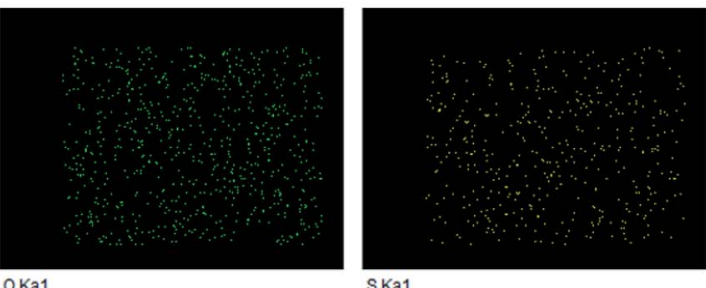

Fig. 4 Elemental mapping ( $, C, O$ and $P t)$ of $P t_{n p}$ anSTDP.

By considering the $1.5 \mathrm{~nm}$ for average diameter of nanoparticles and density of platinum $\left(21.45 \mathrm{~g} \mathrm{~cm}^{-3}\right)$, we can use $N_{\mathrm{Pt}}$ $=d(\pi / 6) D^{3}$ equation for calculation of the number of Pt nanoparticles in one cluster. ${ }^{26-28}$ Where $d$ is the density of Pt nanoparticles and $D$ is the average diameter of nanoparticles. Based on this formula, the number of Pt atoms in the one cluster was calculated as 117 atoms and considering the result of ICP

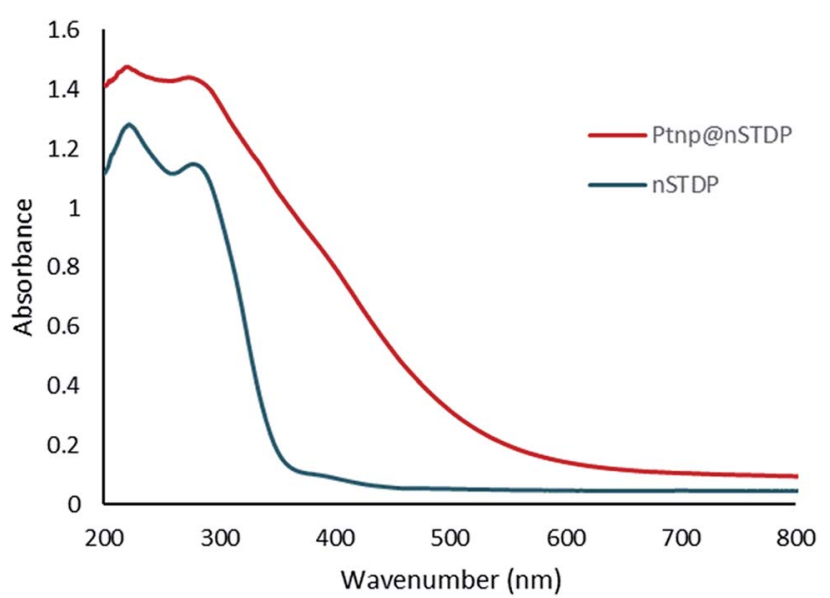

Fig. 5 Diffuse reflectance UV-vis spectrum of $P t_{n p}$ (anSTDP and nSTDP. 

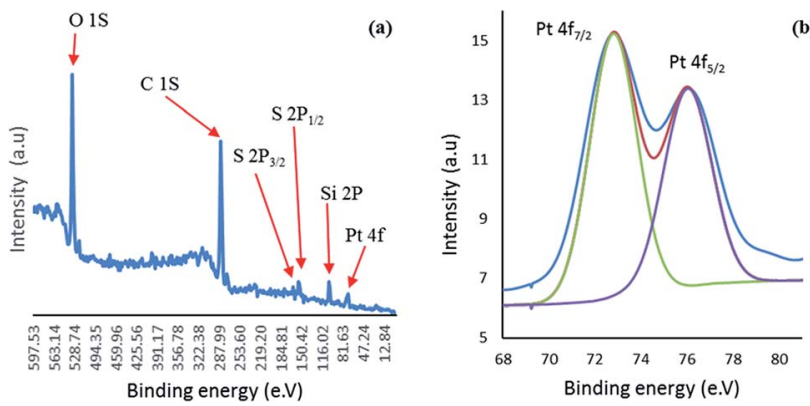

Fig. 6 The XPS spectra of catalyst: (a) the elemental survey scan, (b) Pt $4 f_{7 / 2}$ and $P t 4 f_{5 / 2}$ binding energies.

analysis $(0.06 \mathrm{mmol} \mathrm{Pt}$ per $\mathrm{g})$, there are $31 \times 10^{16} \mathrm{Pt}$ atom in one gram of catalyst.

The overall morphology of $\mathrm{Pt}_{\mathrm{np}} @$ $\mathrm{nSTDP}$ nano-catalyst was evaluated by field emission scanning electron microscopy (FESEM) (Fig. 2). As can be seen the catalyst particles are spherical with an average size of about $50 \mathrm{~nm}$. The presence of $\mathrm{Si}, \mathrm{S}$, and $\mathrm{Pt}$ in the texture of the $\mathrm{Pt}_{\mathrm{np}} @ \mathrm{nSTDP}$ was proved using the energy dispersive X-ray (EDX) results, collected from SEM analysis (Fig. 3). Also, elemental mapping of $\mathrm{Pt}_{\mathrm{np}} @ n S T D P$ displays the uniform dispersion of $\mathrm{Pt}$ nanoparticles in the nSTDP (Fig. 4).

The UV-vis spectrum provided informative evidence for immobilization of the $\mathrm{Pt}$ nanoparticles on thiol dendrimer. The absorption spectrum of thiol dendrimer shows peaks at about 225 and $285 \mathrm{~nm}$ (Fig. 5). The UV-vis spectrum of $\mathrm{Pt}_{\mathrm{np}} @ \mathrm{nSTDP}$ illustrated two peaks, which attributed to thiol dendrimer and two absorption peaks at 216 and $264 \mathrm{~nm}$ which are assigned to Pt nanoparticles, ${ }^{29}$ are vanished the beneath of dendrimer absorption.

The X-ray photoelectron spectroscopy (XPS) was carried out for investigation of the detailed elemental composition and chemical state of the Pt nanoparticles (Fig. 6). The XPS survey spectrum shows the peaks attributed to C 1s, Si 2p, O 1s, S 2p and Pt $4 \mathrm{f}$ in the nano catalyst which is in accordance with EDX results. The doublet peak at 76.0 and $72.8 \mathrm{eV}$ with $\Delta=3.2$ corresponds to Pt $4 \mathrm{f}_{7 / 2}$ and $4 \mathrm{f}_{5 / 2}$, respectively and proved the reduction of $\mathrm{Pt}(\mathrm{II})$ to metallic $\mathrm{Pt}$ in the dendrimer branches. Furthermore, the binding energy for Pt shifted to higher value compared with Pt bulk while it is lower than the binding energy for $\mathrm{Pt}(\mathrm{II}){ }^{30,31}$ This shift in binding energy has been corresponded to two factors: particle size and ligand effect..$^{32}$ Regarding to this shift in ultrafine Pt nanoparticle ${ }^{33,34}$ and the ligand effect in same-size Pt nanoparticles, ${ }^{31}$ this shift can be attributed to effect of ligand and interaction between Pt on the surface of nanoparticles and sulfurs in the dendrimer structure. ${ }^{35-37}$

Thermal gravimeter analysis (TGA) curves for PT-nSiO BCC1-nSiO ${ }_{2}, \mathrm{G} 1, \mathrm{BCC} 2-\mathrm{nSiO}_{2}$ and G2 (nSTDP) were displayed in Fig. S2. $\dagger$ The PT-nSiO $2, \mathrm{BCC}^{-} \mathrm{nSiO}_{2}$ and $\mathrm{G} 1$ decomposed between $350-450{ }^{\circ} \mathrm{C}$ and $\mathrm{BCC} 2-\mathrm{nSiO}_{2}$ showed two distinguished steps related to the decomposition of different functional

Table 1 Optimization of the conditions for synthesis of benzimidazoles and benzothiazoles

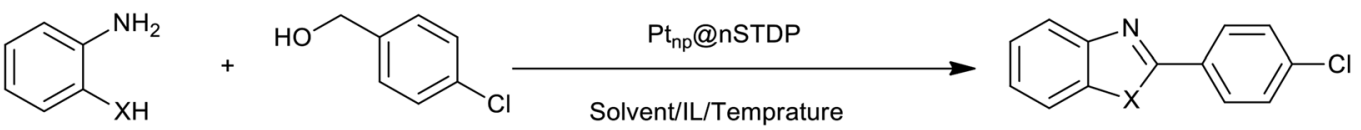

$\mathrm{X}=\mathrm{NH}, \mathrm{S}$

$\mathrm{X}=\mathrm{NH}, \mathrm{S}$

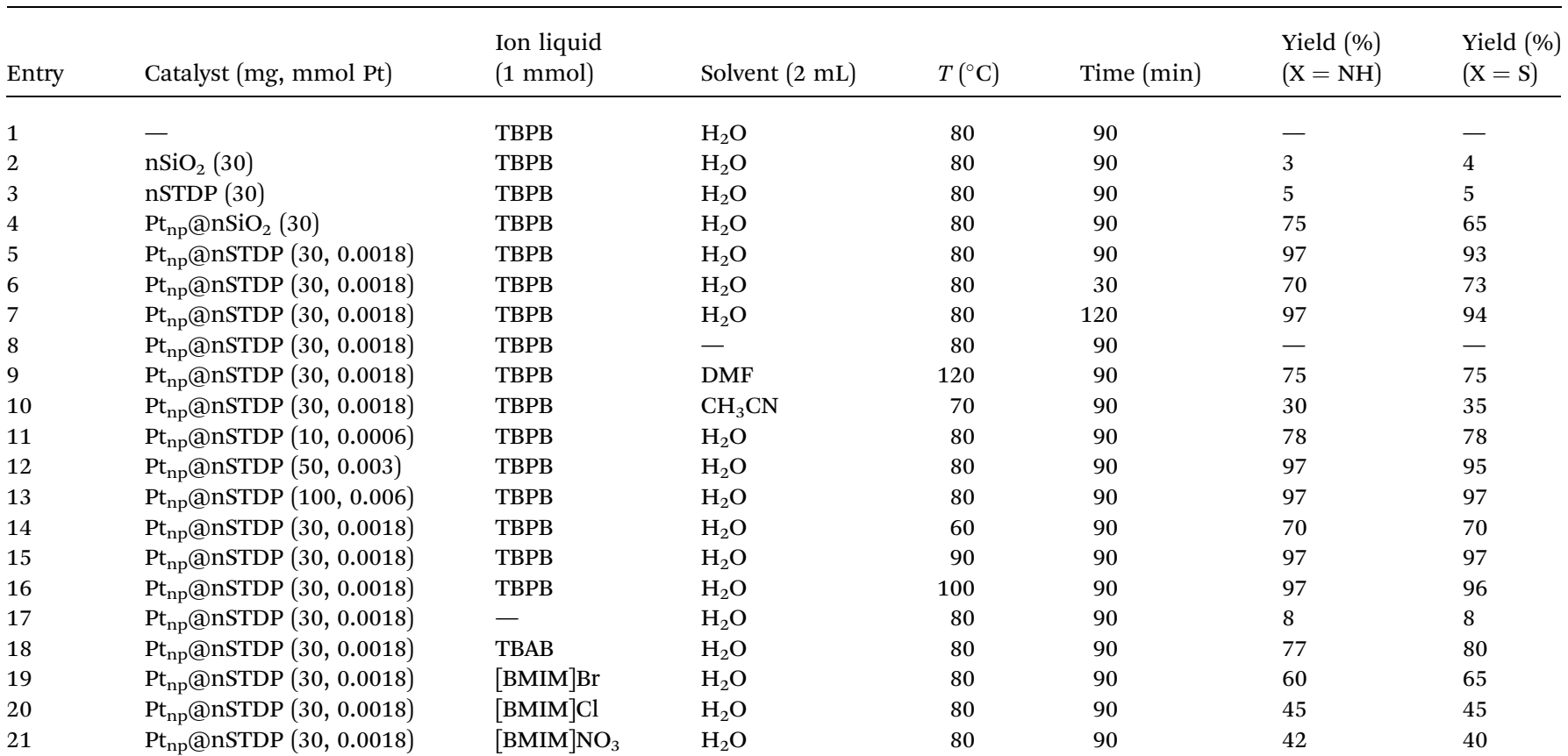


View Article Online

Paper

RSC Advances

Table 2 Synthesis of benzimidazoles catalyzed by Pt $t_{n p}$ anSTDP

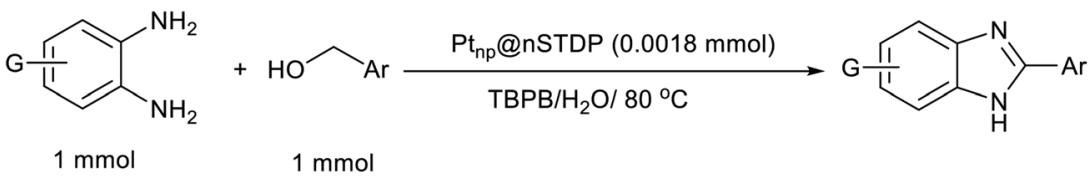

\begin{tabular}{llll}
\hline Entry & $\mathrm{G}$ & Alcohol \\
1 & $\mathrm{H}$
\end{tabular}

2

H

3

$\mathrm{H}$<smiles>OCc1ccc(Cl)cc1</smiles><smiles>Cc1ccc(CO)cc1</smiles>

4

4-Me

5

H

6

4-Cl

7

4-Me

8

H

9

H<smiles>O=[N+]([O-])c1cccc(CO)c1</smiles><smiles>OCc1ccccc1Br</smiles><smiles>OCc1cccc2ccccc12</smiles><smiles>OCc1cccc2ccccc12</smiles><smiles>OCc1c2ccccc2cc2ccccc12</smiles>

10

4-Me<smiles>OCc1cccnc1</smiles><smiles>OCc1c[nH]c2ccccc12</smiles>

11

H<smiles>OCc1cccs1</smiles>

Product

Time (min)

Yield (\%)<smiles>c1ccc(-c2nc3ccccc3[nH]2)cc1</smiles>

95

94

329.8

$\mathrm{Cl}_{\mathrm{H}}^{\mathrm{N}} \mathrm{Cl}$

97

359.2

$\overbrace{\mathrm{H}}^{\mathrm{N}}-\mathrm{CH}_{3}$

120

97

269.4

${ }_{\mathrm{NO}_{2}}^{\mathrm{H}_{3} \mathrm{C}}$

180

89

164.8<smiles>Brc1ccccc1-c1nc2ccccc2[nH]1</smiles>

100

96

300.6

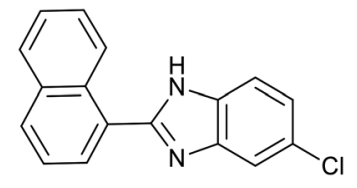

190

90

145.1

(1)

(1)

in

210

89

127.1

(1)

210

90

128.5

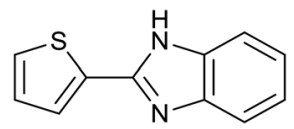

95

91

303.3

This journal is (c) The Royal Society of Chemistry 2020

RSC Adv., 2020, 10, 33137-33147 | 33141 
Table 3 Synthesis of benzothiazoles catalyzed by $\mathrm{Pt}_{\mathrm{np}}$ anSTDP

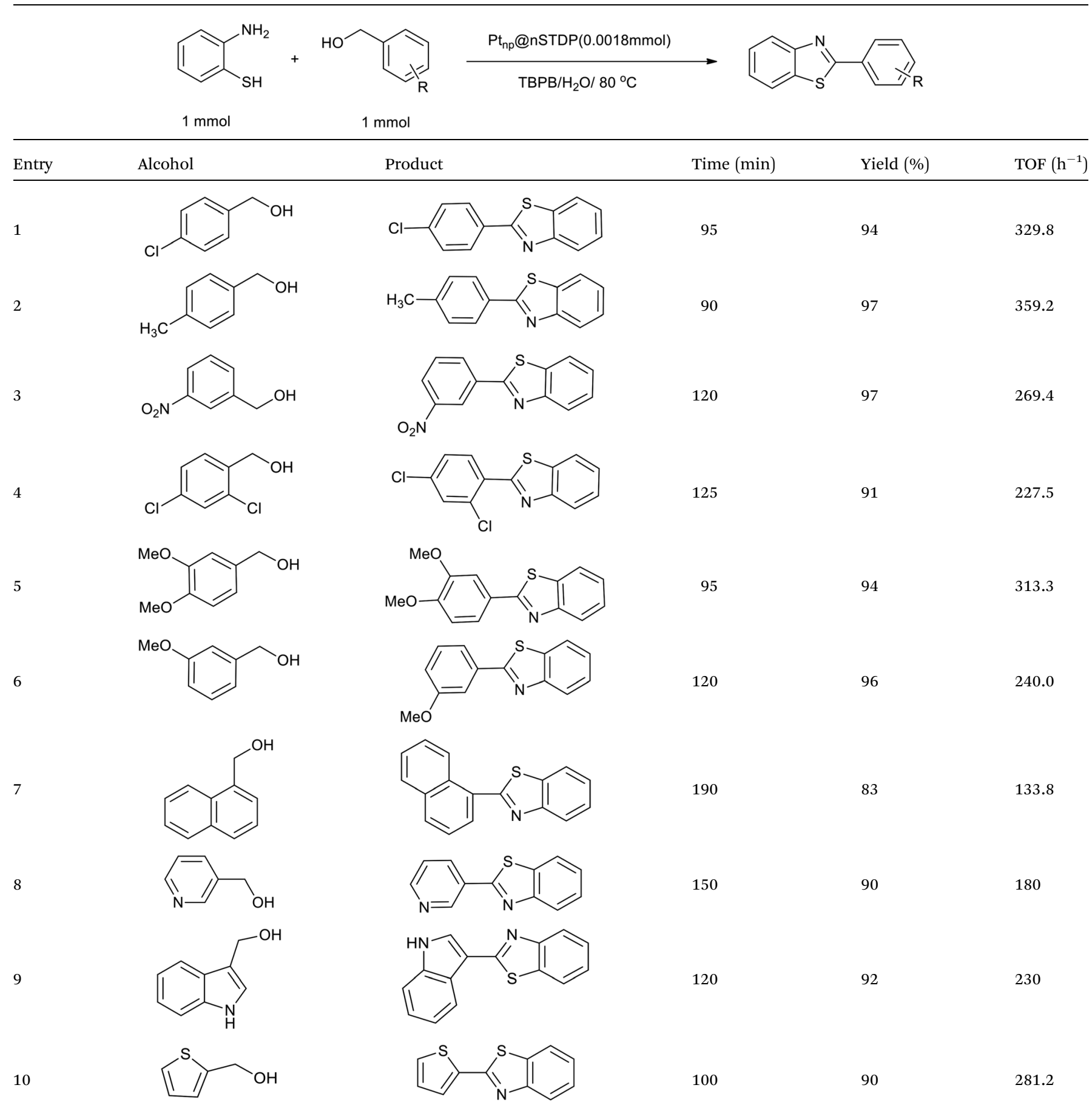

groups. The decomposition of G2 started before $300{ }^{\circ} \mathrm{C}$ is probably due to the presence of different organic moieties in the structure which is not distinct because of variety of functional groups. The weight of residue was decreased as expected with the growth of dendrimer on the nano silica step by step.

\section{Catalytic activity of $\mathbf{P t}_{\mathrm{np}} @ n S T D P$}

After the $\mathrm{Pt}_{\mathrm{np}} @$ $\mathrm{nSTP}$ catalyst was characterized by different technical analyses, its ability was explored in the synthesis of benzimidazoles and benzothiazoles from different benzyl alcohols. In this regard, the reaction between 1,2-phenylenediamine (1 $\mathrm{mmol})$ and 4-chlorobenzylalcohol $(1 \mathrm{mmol})$ was chosen as a model reaction. The effect of different reaction parameters such as type of solvent, temperature, amount of $\mathrm{Pt}_{\mathrm{np}} @ \mathrm{nSTDP}$ catalyst and the influence of ionic liquids was investigated on the reaction yield (Table 1). For the investigation of the efficiency of the catalyst some model reactions were designed and performed in the absence of catalyst and in the 
presence of $\mathrm{nSiO}_{2}, \mathrm{nSTDP} \mathrm{Pt}_{\mathrm{np}} @ \mathrm{nSiO}_{2}$, and $\mathrm{Pt}_{\mathrm{np}} @ \mathrm{nSTDP}$ (Table 1, entries 2-5). The results showed that $\mathrm{Pt}_{\mathrm{np}} @ \mathrm{nSTDP}$ was the most effective catalyst for this reaction. The yield in the absence of catalyst and in the presence of $\mathrm{nSiO}_{2}$ and $\mathrm{nSTDP}$ was negligible which illustrated that $\mathrm{nSiO}_{2}$ and thiol containing dendritic polymer cannot catalyze the reaction.

On the other hand, the $\mathrm{Pt}_{\mathrm{np}} @ \mathrm{nSiO}_{2}$ and $\mathrm{Pt}_{\mathrm{np}} @ \mathrm{nSTDP}$ promoted the reaction yield, and $\mathrm{Pt}_{\mathrm{np}} @ \mathrm{nSTDP}$ showed higher activity. This is due to the well dispersion and small size of $\mathrm{Pt}$ nanoparticles on the nSTDP which provides more active sites for catalyzing the reaction. Investigation on reaction time showed that the best time for gaining the high yield of benzimidazole is $90 \mathrm{~min}$ (Table 1, entries 5-7).

For evaluation of the effect of solvent on the conversion, the reaction was carried out under solvent-free conditions and no product was produced. DMF, chloroform and water as solvent displayed similar yields for DMF and water, and regarding the green chemistry aspects, water was selected as the best solvent.

Furthermore, the amount of catalyst was studied, and $30 \mathrm{mg}$ was chosen as the desired amount. The model reaction was carried out at $60,80,90$ and $100{ }^{\circ} \mathrm{C}$ and the same results were achieved at 80,90 and $100{ }^{\circ} \mathrm{C}$. As expected, the reaction in the absence of ionic liquid was less effective and for more investigation, different ionic liquids were tested in the model reaction and TBPB was selected as phase transfer catalyst (Table 1, entries 17-21). Due to the bigger size of cation, TBPB is more useful than ammonium and imadazolium-based ionic liquids.

The optimization of the parameters continued with reaction of 2-aminothiophenol ( $1 \mathrm{mmol})$ with 4-chlorobenzylalcohol (1 $\mathrm{mmol}$ ) as a model reaction for the optimization of the reaction conditions in the synthesis of benzothiazoles. The data, which are summarized in Table 1, showed similar results obtained in the synthesis of benzimidazoles. Finally, $30 \mathrm{mg}$ of catalyst (containing $0.0018 \mathrm{mmol} \mathrm{Pt}_{\mathrm{np}}$ ) in $\mathrm{H}_{2} \mathrm{O}$ and $1 \mathrm{mg} \mathrm{TBPB}$ at $80{ }^{\circ} \mathrm{C}$

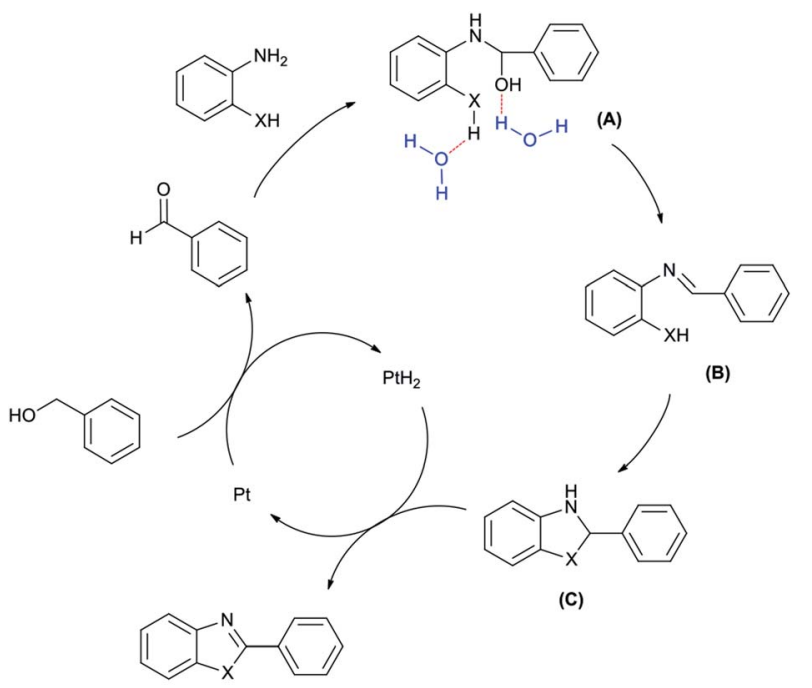

(D)

Fig. 7 Purposed mechanism for synthesis of benzimidazole and benzothiazole in the presence of Pt nanoparticle as catalyst $(X=N H$, S).
(Table 1, entry 5) was used as the best conditions for synthesis of different benzothiazoles.

After determination of ideal reaction conditions, various aromatic benzylalcohols were reacted efficiently with 1,2-phenylenediamine in the presence of catalytic amounts of $\mathrm{Pt}_{\mathrm{np}}$ @nSTDP at $80{ }^{\circ} \mathrm{C}$ to afford the conforming benzimidazoles in high yields (89-97\%) (Table 2). Furthermore, this catalytic system was used for the reaction of different benzylalcohols with 2-aminothiophenol for the synthesis of benzothiazoles. Based on the results in Table 3, the high yield of benzothiazoles (more than 90\%) was obtained for all of the substrates. Two sets of reactions illustrated very excellent performance in the water for both electron-donating and electron-withdrawing alcohols.

Based on the literature, ${ }^{25}$ the plausible mechanism is presented in Fig. 7. In the first step, Pt is converted to $\mathrm{PtH}_{2}$ and catalyzes dehydrogenation of benzyl alcohol to give the corresponding benzaldehyde. $o$-Phenylenediamine (or 2-aminothiophenol) and benzaldehyde produce the $\mathbf{C}$ through intermediate $\mathbf{A}$ and $\mathbf{B}$. In this step, water accelerates the conversion to $\mathbf{C}$ through 5-exo-tet cyclization via a tetrahedral intermediate (Baldwins rules). ${ }^{38,39}$ In the last step, the
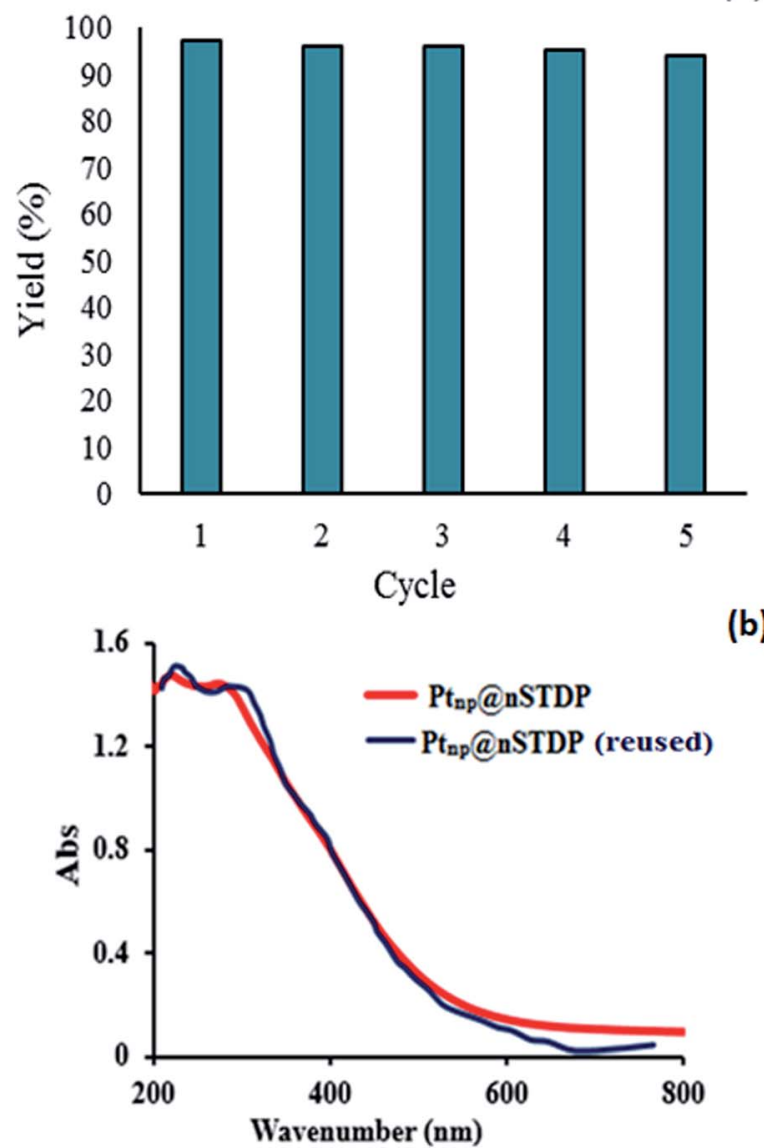

Fig. 8 (a) The recycling of $\mathrm{Pt}_{\mathrm{np}}$ (anSTDP in the synthesis of benzimidazoles between benzylalcohols and phenylenediamine under optimized conditions. (b) UV-vis spectra for fresh Pt $t_{n p}$ anSTDP and reused $\mathrm{Pt}_{\mathrm{np}}$ @nSTDP. 
benzimidazole (or benzothiazole) is produced by dehydrogenation of $\mathrm{PtH}_{2}$ and regeneration of $\mathrm{Pt}$.

\section{Catalyst recycling and reuse}

Since the catalyst recycling is the most important issue for a heterogeneous catalyst from economic, environmental and industrial points of view, we investigated the recycling of the catalyst for the synthesis of benzimidazoles by the reaction between 4-chlorobenzyl alcohol with 1,2-phenylenediamine under the optimized conditions.

After completion of each reaction the catalyst was washed with ethyl acetate and was separated by centrifugation; dried in a vacuum oven at $80{ }^{\circ} \mathrm{C}$ and then reused. As shown in Fig. 8, DR UV-vis spectrum of the catalyst after five catalytic cycles showed no significant change compared to UV-vis spectrum of the fresh catalyst. The amount of $\mathrm{Pt}_{\mathrm{np}} \mathrm{nSTDP}$ catalyst leached was measured by ICP. The result showed that the amount of platinum in the recovered $\mathrm{Pt}_{\mathrm{np}} \mathrm{nSTDP}$ catalyst after the five cycles was $0.0564 \mathrm{mmol} \mathrm{g}^{-1}$ to produce benzimidazole (about $9 \%$ of the initial Pt is leached).

The role of alkanethiols in the stabilization of Pt nanoparticles was investigated after first prepared gold alkanethiolated nanoparticles ${ }^{\mathbf{4 0}}$ and proved in previous literatures. ${ }^{41-43}$ The Pt nanoparticles have also stabilized through encapsulation in dendrimers by protecting them from agglomeration..$^{\mathbf{1 3 4 , 4 5}}$ The combination of these factors has been seen in $\mathrm{Pt}_{\mathrm{np}} @ \mathrm{nSTDP}$ and makes the Pt nanoparticles very stable during reaction via encapsulation it in dendrimer and interaction between nanoparticles and thiol groups.

For comparison of catalytic performance of $\mathrm{Pt}_{\mathrm{np}} @ \mathrm{nSTDP}$, the catalytic activity of similar systems containing $\mathrm{Pt}$ nanoparticles have been presented in Table 4. Pt nanoparticle on the $\mathrm{TiO}_{2}$ was used for the synthesis of benzimidazole that after $24 \mathrm{~h}$, the yield was $60 \%$ and under photoirradiation conditions after $12 \mathrm{~h}, 82 \%$ of benzimidazole was produced (Table 4, entries 1 and 3). In this work, Pt $t_{n p} @ n S T D P$ can produce $97 \%$ of the corresponding benzimidazole after $90 \mathrm{~min}$ in $\mathrm{H}_{2} \mathrm{O}$ which is an excellent result compared to the previous catalysts. Furthermore, the comparison of this catalyst and Pt/ $\mathrm{Al}_{2} \mathrm{O}_{3}$ (Table 4, entry 2) shows a very individual performance of $\mathrm{Pt}_{\mathrm{np}} @ \mathrm{nSTDP}$ for the synthesis of benzothiazole. Very ultrafine Pt nanoparticles and high stability of catalyst during the reaction are two important factors for this excellent operation.

\section{Experimental}

\section{Methods}

Melting points were determined using a Stuart Scientific SMP2 apparatus. ${ }^{1} \mathrm{H}$ and ${ }^{13} \mathrm{C}$ (400 and $100 \mathrm{MHz}$ ) spectra were recorded in $\mathrm{CDCl}_{3}$ solvent on a Bruker-Avance 400 spectrometer. Elemental analyses were done on a LECO, CHNS-932 analyzer. Thermogravimetric analyses (TGA) were carried out on a Mettler TG50 instrument under air flow at a uniform heating rate of $5{ }^{\circ} \mathrm{C} \min ^{-1}$ in the range of $30-600{ }^{\circ} \mathrm{C}$. The UV-vis diffuse reflectance spectra of the samples were recorded by a JASCO V670 spectrophotometer. The X-ray photoelectron spectroscopy (XPS) measurements were performed using a GammadataScienta ESCA200 hemispherical analyzer equipped with an Al $(K=1486.6 \mathrm{eV}) \mathrm{X}$-ray source. The Pt content of the catalyst was measured by an inductively coupled plasma optical emission spectrometry (ICP-OES), using a Jarrell-Ash 1100 ICP analyzer. Scanning electron microscopy measurements were performed

Table 4 Comparison of catalytic performance of $\mathrm{Pt}_{\mathrm{np}}$ (anSTDP with similar systems

2 (ref. 25)

\footnotetext{
${ }^{a}$ Reaction conditions: catalyst $(5 \mathrm{mg})$, alcohol $(750 \mu \mathrm{mol})$, MeCN $(5 \mathrm{~mL})$, under $\mathrm{N}_{2}(1 \mathrm{~atm}), \lambda>300 \mathrm{~nm} .{ }^{b}$ Reaction conditions: catalyst $(1 \mathrm{~mol} \%)$, mesitylene $(1.2 \mathrm{~mL})$, reflux, under $\mathrm{N}_{2} .{ }^{c}$ Reaction conditions: catalyst $(1 \mathrm{~mol} \%)$, mesitylene $(1.2 \mathrm{~mL})$ reflux, under $\mathrm{N}_{2} \cdot{ }^{d}$ Reaction conditions: catalyst (30 mg, containing $0.0018 \mathrm{mmol} \mathrm{Pt} \mathrm{np}$ ), alcohol $\left(1 \mathrm{mmol}\right.$ ) and $1 \mathrm{mmol} \mathrm{TBPB}$ in $\mathrm{H}_{2} \mathrm{O}$ at $80{ }^{\circ} \mathrm{C}$.
} 
on a Hitachi S-4700 field emission-scanning electron microscope (FE-SEM). Transmission electron microscopy (TEM) was carried out on a Philips CM10 analyzer operating at $100 \mathrm{kV}$.

\section{Preparation of Pt nanoparticles immobilized on nano-silica thiolated dendritic polymer (Pt $\left.\mathbf{n}_{\mathrm{np}} @ \mathbf{n S T D P}\right)$}

The nano-silica thiolated dendritic polymer, nSTDP, was prepared according to our previously reported work (see ESI $\dagger$ ). ${ }^{46}$

$\mathrm{K}_{2} \mathrm{PtCl}_{4}(0.01 \mathrm{~g})$ was added to a mixture of $\operatorname{nSTDP}(\mathrm{G} 2)(0.1 \mathrm{~g})$ in $\mathrm{H}_{2} \mathrm{O}(10 \mathrm{~mL})$ and stirred at room temperature for $12 \mathrm{~h}$. A solution of $\mathrm{NaBH}_{4}(0.5 \mathrm{~g}$ in $20 \mathrm{~mL}$ cold deionized water) was added to this mixture and stirred at room temperature for $12 \mathrm{~h}$. At the end of the reaction, the solid material was filtered, washed sequentially with $\mathrm{H}_{2} \mathrm{O}(25 \mathrm{~mL})$ and then dried in a vacuum oven at $80{ }^{\circ} \mathrm{C}$ to obtain the $\mathrm{Pt}_{\mathrm{np}}$ @nSTDP catalyst as a yellow solid.

\section{General procedure for synthesis of benzimidazoles or benzothiazoles in the presence of $\mathrm{Pt}_{\mathrm{np}} @ \mathrm{nSTDP}$ catalyst}

In a round-bottomed flask equipped with a condenser and a magnetic stirrer, a mixture of alcohol ( $1 \mathrm{mmol}), 1,2$-phenylenediamine or 2-aminothiophenol (1 mmol), Pt $\mathrm{t}_{\mathrm{np}} @ n$ STDP (30 mg, containing $0.0018 \mathrm{mmol} \mathrm{Pt}_{\mathrm{np}}$ ) and (1 mmol) tetra- $n$ butylphosphonium bromide (TBPB, $1 \mathrm{mg}$ ) in $\mathrm{H}_{2} \mathrm{O}(2 \mathrm{~mL})$ was stirred at $80{ }^{\circ} \mathrm{C}$. The progress of the reaction was monitored by TLC (eluent: petroleum ether/EtOAc, $2: 1$ for benzimidazoles and petroleum ether/EtOAc, 5:1 for benzothiazoles). The catalyst was separated by filtration and washed with EtOAc (10 $\mathrm{mL}$ ). The filtrate was evaporated, and the crude product was purified by recrystallization from EtOAc or $\mathrm{EtOH}$ to afford the pure benzimidazole. The benzothiazoles was obtained by recrystallization from $n$-hexane/EtOAc $(10: 1)$.

\section{Conclusions}

In conclusion, we synthesized a dendritic polymer, based on nano silica, containing thiol groups for immobilization of $\mathrm{Pt}$ nanoparticles with 1-2 $\mathrm{nm}$ size on the branches of dendrimer ( $\mathrm{Pt}_{\mathrm{np}}$ @nSTDP). This material was used as a unique heterogeneous catalyst for synthesis of benzimidazoles and benzothiazoles from benzyl alcohol derivatives in the water as a green solvent and high yields were obtained for a variety of substrates. Furthermore, with easy separation, the catalyst was reused five times at two reactions without loss of activity which confirms the stability of catalyst during the reaction.

\section{Conflicts of interest}

There are no conflicts to declare.

\section{Notes and references}

1 Y. Deng, Y. Ge, M. Xu, Q. Yu, D. Xiao, S. Yao and D. Ma, Molybdenum carbide: controlling the geometric and electronic structure of noble metals for the activation of O-H and C-H bonds, Acc. Chem. Res., 2019, 52, 3372-3383.
2 K. Na, N. Musselwhite, X. Cai, S. Alayoglu and G. A. Somorjai, Promotional effects of mesoporous zeolites with pt nanoparticle catalysts during reforming of methylcyclopentane, J. Phys. Chem. A, 2014, 118, 8446-8452.

3 S. Bong, B. Jang, D. Han and Y. Piao, Effective electrochemical activation of oleate-residue-fouled pt nanoparticle catalysts for methanol and formic acid oxidation, ACS Omega, 2019, 4, 20330-20334.

4 S. Mei, M. Staub and C. Y. Li, Directed nanoparticle assembly through polymer crystallization, Chem.-Eur. J., 2020, 26, 349-361.

5 S. Proch, J. Herrmannsdörfer, R. Kempe, C. Kern, A. Jess, L. Seyfarth and J. Senker, Pt@MOF-177: synthesis, room-temperature hydrogen storage and oxidation catalysis, Chem.-Eur. J., 2008, 14, 8204-8212.

6 K. An, Q. Zhang, S. Alayoglu, N. Musselwhite, J.-Y. Shin and G. A. Somorjai, High-temperature catalytic reforming of nhexane over supported and core-shell Pt nanoparticle catalysts: role of oxide-metal interface and thermal stability, Nano Lett., 2014, 14, 4907-4912.

7 L. Xu, Y. Zhu, L. Tang, X. Yang and C. Li, Biosensor based on self-assembling glucose oxidase and dendrimer-encapsulated pt nanoparticles on carbon nanotubes for glucose detection, Electroanalysis, 2007, 19, 717-722.

8 A. Boubnov, S. Dahl, E. Johnson, A. P. Molina, S. B. Simonsen, F. M. Cano, S. Helveg, L. J. Lemus-Yegres and J.-D. Grunwaldt, Structure-activity relationships of Pt/ $\mathrm{Al}_{2} \mathrm{O}_{3}$ catalysts for $\mathrm{CO}$ and $\mathrm{NO}$ oxidation at diesel exhaust conditions, Appl. Catal., B, 2012, 126, 315-325.

9 D. E. Doronkin, A. B. Kuriganova, I. N. Leontyev, S. Baier, H. Lichtenberg, N. V. Smirnova and J.-D. Grunwaldt, Electrochemically synthesized $\mathrm{Pt} / \mathrm{Al}_{2} \mathrm{O}_{3}$ oxidation catalysts, Catal. Lett., 2016, 146, 452-463.

10 A. D. Allian, K. Takanabe, K. L. Fujdala, X. Hao, T. J. Truex, J. Cai, C. Buda, M. Neurock and E. Iglesia, Chemisorption of $\mathrm{CO}$ and mechanism of CO oxidation on supported platinum nanoclusters, J. Am. Chem. Soc., 2011, 133, 44984517.

11 M. R. Knecht, M. G. Weir, V. S. Myers, W. D. Pyrz, H. Ye, V. Petkov, D. J. Buttrey, A. I. Frenkel and R. M. Crooks, Synthesis and characterization of $\mathrm{Pt}$ dendrimerencapsulated nanoparticles: effect of the template on nanoparticle formation, Chem. Mater., 2008, 20, 5218-5228.

12 R. M. Anderson, D. F. Yancey, J. A. Loussaert and R. M. Crooks, Multistep galvanic exchange synthesis yielding fully reduced Pt dendrimer-encapsulated nanoparticles, Langmuir, 2014, 30, 15009-15015.

13 H. Lang, R. A. May, B. L. Iversen and B. D. Chandler, Dendrimer-encapsulated nanoparticle precursors to supported platinum catalysts, J. Am. Chem. Soc., 2003, 125, 14832-14836.

$14 \mathrm{H}$. Ye and R. M. Crooks, Electrocatalytic $\mathrm{O}_{2}$ reduction at glassy carbon electrodes modified with dendrimerencapsulated Pt nanoparticles, J. Am. Chem. Soc., 2005, 127, 4930-4934. 
15 A. Landarani Isfahani, I. Mohammadpoor-Baltork, V. Mirkhani, A. R. Khosropour, M. Moghadam and S. Tangestaninejad, Pd nanoparticles immobilized on nanosilica triazine dendritic polymer: a reusable catalyst for the synthesis of mono-, di-, and trialkynylaromatics by sonogashira cross-coupling in water, Eur. J. Org. Chem., 2014, 5603-5609.

16 M. Liu and J. M. Fréchet, Designing dendrimers for drug delivery, Pharm. Sci. Technol. Today, 1999, 2, 393-401.

17 G. Chen, J. Kumar, A. Gregory and M. H. Stenzel, Efficient synthesis of dendrimers via a thiol-yne and esterification process and their potential application in the delivery of platinum anti-cancer drugs, Chem. Commun., 2009, 62916293.

18 J. Alvarez, J. Liu, E. Román and A. E. Kaifer, Water-soluble platinum and palladium nanoparticles modified with thiolated $\beta$-cyclodextrin, Chem. Commun., 2000, 1151-1152.

19 O. Akyıldırım, H. Yüksek, H. Saral, İ. Ermiş, T. Eren and M. L. Yola, Platinum nanoparticles supported on nitrogen and sulfur-doped reduced graphene oxide nanomaterial as highly active electrocatalysts for methanol oxidation, $J$. Mater. Sci.: Mater. Electron., 2016, 27, 8559-8566.

20 C. Wang, G. Zhu, J. Li, X. Cai, Y. Wei, D. Zhang and S. Qiu, Rigid nanoscopic containers for highly dispersed, stable metal and bimetal nanoparticles with both size and site control, Chem.-Eur. J., 2005, 11, 4975-4982.

21 Y. Kumar and H. Ila, Domino synthesis of 2-substituted benzothiazoles by base-promoted intramolecular $\mathrm{C}-\mathrm{S}$ bond formation, Org. Lett., 2019, 21, 7863-7867.

22 W.-X. Xu, X.-Q. Dai and J.-Q. Weng, $\mathrm{K}_{2} \mathrm{~S}_{2} \mathrm{O}_{8}$-mediated hydroxyalkylation of benzothiazoles with alcohols in aqueous solution, ACS Omega, 2019, 4, 11285-11292.

23 A. Ekbote, S. M. Mobin and R. Misra, Structure-property relationship in multi-stimuli responsive $\mathrm{D}-\mathrm{A}-\mathrm{A}^{\prime}$ benzothiazole functionalized isomers, J. Mater. Chem. C, 2018, 6, 10888-10901.

24 Y. Shiraishi, Y. Sugano, S. Tanaka and T. Hirai, One-Pot Synthesis of Benzimidazoles by Simultaneous Photocatalytic and Catalytic Reactions on ${\mathrm{Pt} @ \mathrm{TiO}_{2}}$ Nanoparticles, Angew. Chem., 2010, 122, 1700-1704.

25 C. Chaudhari, S. H. Siddiki and K.-i. Shimizu, Acceptorless dehydrogenative synthesis of benzothiazoles and benzimidazoles from alcohols or aldehydes by heterogeneous Pt catalysts under neutral conditions, Tetrahedron Lett., 2015, 56, 4885-4888.

26 A. Daneshvar, M. Moghadam, S. Tangestaninejad, V. Mirkhani, I. Mohammadpoor-Baltork and A. Khalili, Ruthenium hydride complex supported on gold nanoparticle cored triazine dendrimers for $\mathrm{C}-\mathrm{C}$ coupling reactions, Organometallics, 2016, 35, 1747-1755.

27 K. R. Gopidas, J. K. Whitesell and M. A. Fox, Synthesis, characterization, and catalytic applications of a palladiumnanoparticle-cored dendrimer, Nano Lett., 2003, 3, 17571760.

28 W. Yang, M. Chen, W. Knoll and H. Deng, Synthesis of hexanedithiolate/decanethiolate mixed monolayer protected gold clusters and scanning tunneling microscope tip induced patterning on the clusters/Au (111) surface, Langmuir, 2002, 18, 4124-4130.

29 E. Gharibshahi and E. Saion, Influence of dose on particle size and optical properties of colloidal platinum nanoparticles, Int. J. Mol. Sci., 2012, 13, 14723-14741.

30 W. Moddeman, J. Blackburn, G. Kumar, K. Morgan, R. G. Albridge and M. Jones, Photoelectron spectroscopy of coordination compounds. III. Comparison of platinum (II) and platinum (IV) compounds, Inorg. Chem., 1972, 11, 1715-1717.

31 X. Fu, Y. Wang, N. Wu, L. Gui and Y. Tang, Surface modification of small platinum nanoclusters with alkylamine and alkylthiol: an XPS study on the influence of organic ligands on the Pt $4 \mathrm{f}$ binding energies of small platinum nanoclusters, J. Colloid Interface Sci., 2001, 243, 326-330.

32 Y.-T. Kim and T. Mitani, Surface thiolation of carbon nanotubes as supports: a promising route for the high dispersion of Pt nanoparticles for electrocatalysts, J. Catal., 2006, 238, 394-401.

33 C. Yang, Q. Jiang, W. Li, H. He, L. Yang, Z. Lu and H. Huang, Ultrafine Pt nanoparticle-decorated 3D hybrid architectures built from reduced graphene oxide and MXene nanosheets for methanol oxidation, Chem. Mater., 2019, 31, 9277-9287.

34 Z. Xing, C. Han, D. Wang, Q. Li and X. Yang, Ultrafine Pt nanoparticle-decorated $\mathrm{Co}(\mathrm{OH})_{2}$ nanosheet arrays with enhanced catalytic activity toward hydrogen evolution, ACS Catal., 2017, 7, 7131-7135.

35 H. I. Lee, S. H. Joo, J. H. Kim, D. J. You, J. M. Kim, J.-N. Park, H. Chang and C. Pak, Ultrastable Pt nanoparticles supported on sulfur-containing ordered mesoporous carbon via strong metal-support interaction, J. Mater. Chem., 2009, 19, 59345939.

36 R. Ahmadi and M. K. Amini, Synthesis and characterization of Pt nanoparticles on sulfur-modified carbon nanotubes for methanol oxidation, Int. J. Hydrogen Energy, 2011, 36, 72757283.

37 K. Kwon, S.-a. Jin, C. Pak, H. Chang, S. H. Joo, H. I. Lee, J. H. Kim and J. M. Kim, Enhancement of electrochemical stability and catalytic activity of Pt nanoparticles via strong metal-support interaction with sulfur-containing ordered mesoporous carbon, Catal. Today, 2011, 164, 186-189.

38 H. Hikawa, R. Ichinose, S. Kikkawa and I. Azumaya, Palladium-catalyzed dehydrogenation of benzyl alcohols for construction of 2-arylbenzimidazoles "on water", Asian J. Org. Chem., 2018, 7, 416-423.

39 Y.-S. Lee, Y.-H. Cho, S. Lee, J.-K. Bin, J. Yang, G. Chae and C.-H. Cheon, Significant facilitation of metal-free aerobic oxidative cyclization of imines with water in synthesis of benzimidazoles, Tetrahedron, 2015, 71, 532-538.

40 M. Brust, M. Walker, D. Bethell, D. J. Schiffrin and R. Whyman, Synthesis of thiol-derivatised gold nanoparticles in a two-phase liquid-liquid system, J. Chem. Soc., Chem. Commun., 1994, 801-802.

41 J. Yang, J. Y. Lee, T. Deivaraj and H.-P. Too, An improved procedure for preparing smaller and nearly monodispersed 
thiol-stabilized platinum nanoparticles, Langmuir, 2003, 19, 10361-10365.

42 W. Tu, K. Takai, K.-i. Fukui, A. Miyazaki and T. Enoki, Interface effect on the electronic structure of alkanethiolcoated platinum nanoparticles, J. Phys. Chem. B, 2003, 107, 10134-10140.

43 C. Yee, M. Scotti, A. Ulman, H. White, M. Rafailovich and J. Sokolov, One-phase synthesis of thiol-functionalized platinum nanoparticles, Langmuir, 1999, 15, 4314-4316.

44 R. W. Scott, A. K. Datye and R. M. Crooks, Bimetallic palladium-platinum dendrimer-encapsulated catalysts, $J$. Am. Chem. Soc., 2003, 125, 3708-3709.
45 R. Crooks and M. Zhao, Dendrimer-encapsulated Pt nanoparticles: synthesis, characterization, and applications to catalysis, Adv. Mater., 1999, 11, 217-220.

46 M. Zakeri, M. Moghadam, V. Mirkhani, S. Tangestaninejad, I. Mohammadpoor-Baltork and Z. Pahlevanneshan, Synthesis and characterization of a host (a new thiol based dendritic polymer)-guest (Pd nanoparticles) nanocomposite material: an efficient and reusable catalyst for C-C coupling reactions, RSC Adv., 2016, 6, 104608104619. 